\title{
MicroRNAs associated with small bowel neuroendocrine tumours and their metastases
}

\author{
Helen C Miller1,+, Adam E Frampton ${ }^{1,+}$, Anna Malczewska1,2, Silvia Ottaviani1, \\ Euan A Stronach', Rashpal Flora3, Daniel Kaemmerer4, Gert Schwach5, \\ Roswitha Pfragner5, Omar Faiz6, Beata Kos-Kudła², George B Hanna7, \\ Justin Stebbing ${ }^{2, \ddagger}$, Leandro Castellano ${ }^{2, \ddagger}$ and Andrea Frilling ${ }^{1, \pm}$ \\ 1Department of Surgery and Cancer, Imperial College, Hammersmith Hospital Campus, London, UK \\ 2Department of Pathophysiology and Endocrinology, School of Medicine with the Division of Dentistry \\ in Zabrze, Medical University of Silesia, Katowice, Poland \\ ${ }^{3}$ Department of Histopathology, Imperial College Healthcare NHS Trust, Hammersmith Hospital, London, UK \\ ${ }^{4}$ Zentralklinik Bad Berka GmbH, Robert-Koch-Allee, Bad Berka, Germany \\ IInstitute of Pathophysiology, Center for Molecular Medicine, Medical University of Graz, Graz, Austria \\ 6St Mark's Hospital, Harrow, UK \\ ${ }^{7}$ Academic Surgical Unit, Department of Surgery and Cancer, Imperial College, St Mary's Campus, London, UK \\ ${ }^{\dagger}(\mathrm{H}$ C Miller and A E Frampton contributed equally as co-first authors) \\ ‡(J Stebbing, L Castellano and A Frilling contributed equally as co-senior authors)
}

Correspondence should be addressed to A Frilling Email a.frilling@imperial.ac.uk

\begin{abstract}
Novel molecular analytes are needed in small bowel neuroendocrine tumours (SBNETs) to better determine disease aggressiveness and predict treatment response. In this study, we aimed to profile the global miRNome of SBNETs, and identify microRNAs (miRNAs) involved in tumour progression for use as potential biomarkers. Two independent miRNA profiling experiments were performed $(n=90)$, including primary SBNETs $(n=28)$, adjacent normal small bowel (NSB; $n=14)$, matched lymph node (LN) metastases $(n=24)$, normal LNs $(n=7)$, normal liver $(n=2)$ and liver metastases $(n=15)$. We then evaluated potentially targeted genes by performing integrated computational analyses. We discovered 39 miRNAs significantly deregulated in SBNETs compared with adjacent NSB. The most upregulated (miR-204-5p, miR-7-5p and miR-375) were confirmed by qRT-PCR. Two miRNAs (miR-1 and miR-143-3p) were significantly downregulated in LN and liver metastases compared with primary tumours. Furthermore, we identified upregulated gene targets for miR-1 and miR-143-3p in an existing SBNET dataset, which could contribute to disease progression, and show that these miRNAs directly regulate FOSB and NUAK2 oncogenes. Our study represents the largest global miRNA profiling of SBNETs using matched primary tumour and metastatic samples. We revealed novel miRNAs deregulated during SBNET disease progression, and important miRNA-mRNA interactions. These miRNAs have the potential to act as biomarkers for patient stratification and may also be able to guide treatment decisions. Further experiments to define molecular mechanisms and validate these miRNAs in larger tissue cohorts and in biofluids are now warranted.
\end{abstract}

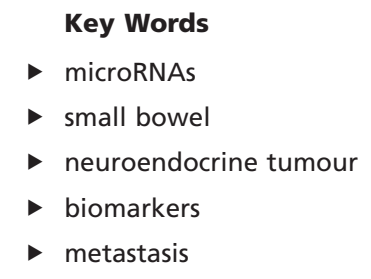

Endocrine-Related Cancer (2016) 23, 711-726 (c) 2016 Society for Endocrinology Printed in Great Britain
Published by Bioscientifica Ltd. 


\section{Introduction}

Small bowel neuroendocrine tumours (SBNETs) account for the most common neuroendocrine neoplasm of the gastroenteropancreatic (GEP) system (Lawrence et al. 2011). Their incidence is steadily increasing; in males, 2.7 -fold overall change to 0.46 per 100,000 per year in England for the period 1971-2006 (Ellis et al. 2010) and from 0.38 to 1.08 per 100,000 for the period $1973-2007$ based on the National Cancer Institute Surveillance, Epidemiology and End Results (SEER) cancer registry in the United States (Lawrence et al. 2011, Fraenkel et al. 2012).

Most SBNETs are low-grade lesions; nevertheless, up to $90 \%$ of patients with SBNET have lymph node metastases, and in $45-70 \%$ of cases, liver metastases are present at the initial diagnosis (Lawrence et al. 2011, Norlén et al. 2012, Miller et al. 2014). These intriguing characteristics contribute to a 5-year survival of less than $60 \%$ from diagnosis of liver metastases (Ahmed et al. 2009) compared to about $80 \%$ in patients with loco-regionally limited disease (Norlén et al. 2012). The lack of specific and sensitive biomarkers to stratify NETs according to subtype, determine tumour burden, assess disease progression, select patients for individualised treatment and monitor treatment efficacy is a key issue in management of NETs (Modlin et al. 2008, Frilling et al. 2014).

MicroRNAs (miRNAs) are small endogenous noncoding RNAs 17-25 nucleotides in length that play important post-transcriptional roles in gene regulation by targeting mRNAs, occasionally for direct cleavage, but usually for either translational repression or transcript destabilisation. miRNAs are involved in most developmental and physiological processes and their deregulation is linked to many human diseases, including cancer (Siomi \& Siomi 2010, Krell et al. 2015). Several studies have shown that miRNAs can act as both oncogenes and tumour suppressors and expression profiling has associated specific miRNAs with a variety of cancers in the hope of developing tumour subtype-specific signatures (Calin \& Croce 2006, Esquela-Kerscher \& Slack 2006, Weber et al. 2006, Zhang et al. 2007). Recently, miRNAs have been identified as novel biomarkers (diagnostic and/ or prognostic), as well as targets for molecular therapy in various tumours, and have the potential to be utilised in the clinical setting (Osaki et al. 2008, Yip et al. 2011, Frampton et al. 2014, Toiyama et al. 2014, Zhu et al. 2014, Sandhu et al. 2015).

In GEP NETs, data on miRNAs are limited, although their role has been well assessed in those of pancreatic origin (PNETs) (Luzi \& Brandi 2011). Indeed, specific miRNAs signatures have been shown to discriminate PNETs from acinar pancreatic tumours (Roldo et al. 2006), cystic forms of PNETs from other pancreatic cystic lesions (Matthaei et al. 2012) and PNETs from pancreatic ductal adenocarcinoma (Li et al. 2013a). Although there have been two small miRNA profiling studies of SBNETs

A

B

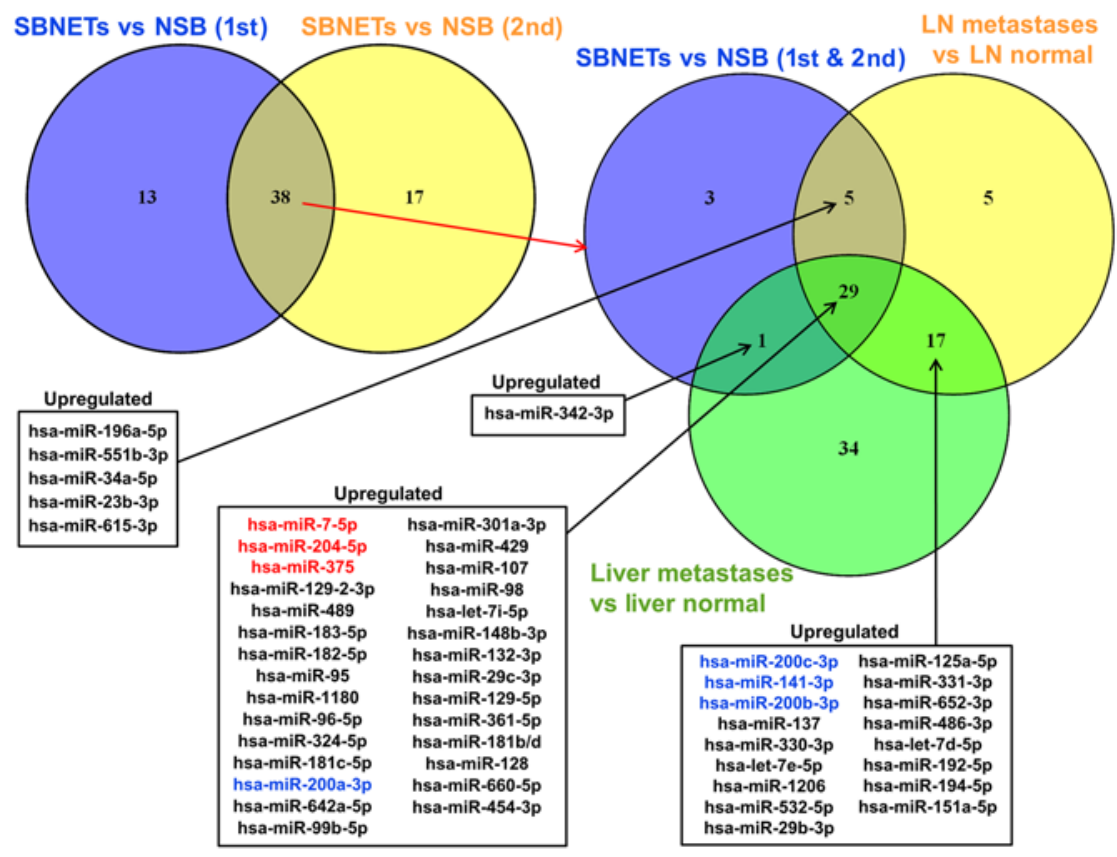

Figure 1

Venn diagrams showing upregulated miRNAs in primary SBNETs and their metastases compared to normal tissues. (A) Upregulated miRNAs in SBNETs vs NSB. Combining the two NanoString nCounter profiling experiments ( 1 st $\& 2 \mathrm{nd}$ ) revealed 38 upregulated miRNAs in the intersection (log2 fold change $(F C) \geq 1.5$ and adjusted $P<0.05$ ). (B) Upregulated miRNAs in $\mathrm{LN}$ and liver metastases versus primary SBNETs. A "signature" of 29 upregulated miRNAs for SBNETs and their metastases vs normal tissues was discovered (central green intersection). Furthermore, 17 upregulated miRNAs were identified in both LN and liver metastases versus normal tissues, including members of the miR-200 family (miR-200a-3p, miR-200b-3p, miR-200c-3p and miR-141-3p). (Key: Red line indicates these common candidate miRNAs upregulated in SBNETs were used in the next blue circle; LN, lymph node; NSB, adjacent normal small bowel; SBNET, small bowel neuroendocrine tumour). A full colour version of this figure is available at http://dx.doi.org/10.1530/ERC-16-0044. 
Table 1 Most significantly deregulated miRNAs in SBNETs vs adjacent normal small bowel (NSB).

\begin{tabular}{|c|c|c|}
\hline $\begin{array}{l}\text { Deregulated miRNA } \\
\text { (1st profiling) }\end{array}$ & Log2 fold-change & ${ }^{\text {a Adjusted } P \text { value }}$ \\
\hline $\operatorname{miR}-7-5 p^{b, c, d}$ & 6.4 & 2.57E-114 \\
\hline $\operatorname{miR}-375 b, c, d$ & 5.6 & $6.30 \mathrm{E}-67$ \\
\hline $\operatorname{miR}-204-5 p^{b, c, d}$ & 5.3 & $2.44 E-67$ \\
\hline miR-129-2-3pc,d & 4.7 & $2.65 E-28$ \\
\hline $\operatorname{miR}-489 c, d$ & 4.0 & $7.32 E-30$ \\
\hline $\operatorname{miR}-183-5 p^{c, d, e}$ & 3.9 & $1.43 E-26$ \\
\hline $\operatorname{miR}-182-5 p^{c, d, e}$ & 3.9 & $1.21 \mathrm{E}-21$ \\
\hline $\operatorname{miR}-95 c, d$ & 3.8 & $5.83 E-43$ \\
\hline $\operatorname{miR}-1180^{c, d}$ & 3.6 & $6.29 E-45$ \\
\hline miR-196a-5pc,e & 3.3 & 1.18E-09 \\
\hline $\operatorname{miR}-96-5 p^{c, d, e}$ & 3.2 & 9.31E-19 \\
\hline miR-324-5pc,d & 3.2 & 1.13E-24 \\
\hline $\operatorname{miR}-181 c-5 p^{c, d}$ & 3.1 & 3.37E-41 \\
\hline $\operatorname{miR}-200 a-3 p^{c, d, e}$ & 3.1 & $2.17 E-22$ \\
\hline $\operatorname{miR}-342-3 p^{c, d}$ & 2.9 & 8.62E-18 \\
\hline $\operatorname{miR}-642 a-5 p^{c, d}$ & 2.9 & $3.72 E-40$ \\
\hline miR-330-3p & 2.8 & $6.36 \mathrm{E}-37$ \\
\hline $\operatorname{miR}-551 b-3 p^{c, e}$ & 2.7 & $1.46 \mathrm{E}-10$ \\
\hline miR-135a-5p & 2.7 & 1.63E-08 \\
\hline miR-486-3p & 2.7 & $6.63 E-15$ \\
\hline $\operatorname{miR}-99 b-5 p^{c, d}$ & 2.6 & $6.26 \mathrm{E}-18$ \\
\hline $\operatorname{miR}-301 a-3 p^{c, d}$ & 2.5 & $9.06 \mathrm{E}-23$ \\
\hline $\operatorname{miR}-429 c, d$ & 2.5 & $1.18 \mathrm{E}-18$ \\
\hline miR-331-3p & 2.5 & $2.12 \mathrm{E}-22$ \\
\hline miR-107c,d & 2.5 & $5.77 E-14$ \\
\hline miR-98c,d & 2.4 & $2.88 \mathrm{E}-15$ \\
\hline let-7i-5pc,d & 2.3 & $9.27 \mathrm{E}-16$ \\
\hline $\operatorname{miR}-148 b-3 p^{c, d}$ & 2.3 & $1.74 \mathrm{E}-22$ \\
\hline miR-29b-3p & 2.3 & $1.28 \mathrm{E}-15$ \\
\hline miR-532-5p & 2.3 & 1.09E-13 \\
\hline miR-200b-3p & 2.2 & $2.76 \mathrm{E}-11$ \\
\hline let-7e-5p & 2.2 & 7.68E-11 \\
\hline $\operatorname{miR}-132-3 p^{c, d}$ & 2.2 & 1.71E-11 \\
\hline $\operatorname{miR}-29 c-3 p^{c, d}$ & 2.2 & $1.40 \mathrm{E}-15$ \\
\hline miR-125a-5p & 2.2 & 2.07E-13 \\
\hline miR-129-5pc,d & 2.0 & 8.17E-09 \\
\hline $\operatorname{miR}-361-5 p^{c, d}$ & 2.0 & $5.55 \mathrm{E}-13$ \\
\hline $\operatorname{miR}-181 \mathrm{~b} / \mathrm{d}^{\mathrm{c}, \mathrm{d}}$ & 1.9 & $2.83 E-14$ \\
\hline let-7d-5p & 1.9 & $5.66 \mathrm{E}-10$ \\
\hline $\operatorname{miR}-34 a-5 p^{c}$ & 1.9 & $1.78 \mathrm{E}-08$ \\
\hline $\operatorname{miR}-128 c, d$ & 1.8 & 5.95E-21 \\
\hline miR-421 & 1.7 & $2.31 \mathrm{E}-17$ \\
\hline miR-652-3p & 1.6 & 5.52E-10 \\
\hline $\operatorname{miR}-660-5 p^{c, d}$ & 1.6 & 1.32E-12 \\
\hline $\operatorname{miR}-23 b-3 p^{c}$ & 1.6 & 1.41E-06 \\
\hline $\operatorname{miR}-615-3 p^{c}$ & 1.6 & 2.77E-14 \\
\hline let-7g-5p & 1.6 & 3.18E-06 \\
\hline miR-15a-5p & 1.5 & 4.07E-07 \\
\hline miR-505-3p & 1.5 & 7.15E-12 \\
\hline miR-29a-3p & 1.5 & 3.15E-08 \\
\hline $\operatorname{miR}-454-3 p^{c, d}$ & 1.5 & $6.38 \mathrm{E}-11$ \\
\hline miR-451a & -1.6 & 8.52E-05 \\
\hline miR-31-5pe & -1.6 & 7.20E-14 \\
\hline
\end{tabular}

Deregulated miRNA

Log2 fold-change

miR-137 3.5

miR-489c,d

$\operatorname{miR}-375^{b, c, d}$

$\operatorname{miR}-95^{c, d}$

miR-7-5pb,c,d

miR-301a-3p $p^{c, d}$

miR-642a-5pc,d

miR-204-5p $p^{b, c, d}$

miR-129-2-3pc,d

miR-181c-5pc,d

$\operatorname{miR}-183-5 p^{c, d, e}$

miR-26a-5p

miR-107c,d

miR-429c, d

miR-98c,d

miR-182-5pc,d,e

miR-34a-5pc

miR-454-3pc,d

miR-200a-3pc,d,e

miR-96-5pc,d,e

miR-148b-3pc,d

miR-340-5p

miR-551b-3pc

miR-1206

miR-129-5pc,d

miR-582-5p

miR-660-5pc,d

let-7f-5p

miR-362-3p

miR-4284

miR-99b-5pc,d

miR-29c-3pc,d

miR-30c-5p

miR-342-3pc,d

miR-324-5pc,d

miR-505-3pc

miR-374b-5p

miR-128c,d

miR-196a-5pc,e

miR-135a-5p

miR-30b-5p

et-7i-5p $p^{c, d}$

miR-421

miR-132-3pc,d

miR-24-3p

miR-27b-3p

miR-16-5p

miR-1180c,d

miR-664-3p

miR-361-5pc,d

$\operatorname{miR}-23 b-3 p^{c}$

$\mathrm{miR}-181 \mathrm{~b} / \mathrm{dc}$, d

et-7c

miR-1468

miR-615-3pc

miR-31-5pe

miR-3180

\section{5}

3.4

3.2

3.0

2.9

2.6

2.6

2.6

2.5

2.3

2.3

2.2

2.2

2.2

2.1

2. 1

2. 1

2.1

2.1

2. 1

2.1

2.1

2.0

2.0

2.0

2.0

2.0

2.0

2.0

2.0

2.0

1.9

1.9

1.9

1.9

1.9

1.9

1.9

1.9

1.9

1.8

1.8

1.8

1.8

1.8

1.7

1.6

1.6

1.6

1.6

1.6

1.6

1.5

1.5

1.5

$-1.5$

$-3.3$ adjusted $\boldsymbol{P}$ value

1.01E-05

$1.31 \mathrm{E}-05$

7.21E-05

4.38E-05

0.000662392

0.00021524

0.000648626

0.002747422

0.003108321

0.000662392

0.009328868

0.003108321

0.002747422

0.007482279

0.002950183

0.014094932

0.003307545

0.001074461

0.011254433

0.016459461

0.003108321

0.003108321

0.015881653

0.016010957

0.011434466

0.003108321

0.005523635

0.011434466

0.006553207

0.003509808

0.00481433

0.009328868

0.005946993

0.012856933

0.00481433

0.003108321

0.003899893

0.003108321

0.034641355

0.035737367

0.019875614

0.014896097

0.00065961

0.01162531

0.011434466

0.020224505

0.037832967

0.019407266

0.002880957

0.003108321

0.034602111

0.003108321

0.040776702

0.020445252

0.009328868

0.000648626

2.71E-08

Continued 
Table 1 (Continued)

\begin{tabular}{l} 
Deregulated miRNA \\
(1st profiling) \\
\hline miR-378ge \\
miR-4516 \\
miR-148a-3p \\
miR-378a/le \\
miR-215e
\end{tabular}

\begin{tabular}{c}
\hline Log2 fold-change \\
\hline-1.7 \\
-1.8 \\
-1.8 \\
-2.1 \\
-3.4
\end{tabular}

\begin{tabular}{lll}
\hline aAdjusted $\boldsymbol{P}$ value & & $\begin{array}{l}\text { Deregulated miRNA } \\
\text { (2nd profiling) }\end{array}$ \\
\hline $5.88 \mathrm{E}-16$ & & \\
$8.32 \mathrm{E}-05$ & & \\
$1.33 \mathrm{E}-13$ & & \\
$2.52 \mathrm{E}-22$ & & \\
$8.56 \mathrm{E}-22$ & &
\end{tabular}

Key: For visualization, we included those miRNAs with log2 FC \pm 1.5 . a $P$ value adjusted using false discovery rate (FDR) method; bThese miRNAs were validated by qRT-PCR. miRNAs highlighted in gray were deregulated in both profiling experiments; CThese miRNAs are also upregulated in lymph node metastases vs normal lymph nodes; 'These miRNAs are also upregulated in liver metastases vs normal liver; eThese miRNAs were found to be deregulated in the study by Li and coworkers (2013b).

(Ruebel et al. 2010, Li et al. 2013b), the role of these molecules as biomarkers in this tumour type remains largely unknown. We aimed to assess the global miRNA expression of primary SBNETs, matched LNs and liver metastases and normal tissues, to discover possible biomarkers of tumourigenesis and disease progression.

\section{Materials and methods}

The materials and methods can be found in the Supplementary Materials and methods (see section of supplementary data given at the end of this article). This includes details about the patient samples included; RNA isolation; NanoString miRNA profiling; bioinformatic analyses; gene ontology and pathway analyses; qRT-PCR; cell culture; luciferase reporter assays and immunoblotting.

\section{Results}

NanoString nCounter profiling reveals a common miRNA signature for small bowel NETs and their lymph node and liver metastases compared with normal tissues

We assessed 800 known human miRNAs in 90 patient samples. The 1st profiling cohort included primary SBNETs $(n=15)$, adjacent normal small bowel (NSB; $n=12)$, matched LN metastases $(n=9)$, normal LNs $(n=7)$, normal liver $(n=2)$ and liver metastases $(n=2$; Supplementary Table 1 , see section on supplementary data given at the end of this article). The 2 nd profiling cohort included SBNET $(n=13)$, NSB $(n=2)$, LN metastases $(n=15)$ and liver metastases $(n=13)$. Combining the two NanoString nCounter experiments, we revealed 38 upregulated miRNAs (intersection in Fig. $1 \mathrm{~A}$ and Table 1) and 1 downregulated miRNA (all log2 fold change (FC) $\leq 1.5$ or $\geq 1.5$; adjusted $P<0.05$ ) in SBNETs vs NSB (Table 1 ; Supplementary Fig. 1A and Table 2).
Next, we investigated the miRNA signature of infiltrated LNs versus normal LNs, as well as liver metastases versus normal liver (Fig. 1B; Supplementary Fig. 1B and Table 2). Strikingly, we found significant overlap between the upregulated miRNAs in primary SBNETs and their metastases compared with their normal tissues, and identified a 29 miRNA signature for this disease (central green intersection in Fig. 1B). We then confirmed increased expression of the top three upregulated miRNAs (miR-204-5p, miR-7-5p and miR-375) in SBNETs compared with NSB using qRT-PCR, thereby also validating our nCounter miRNA expression profile microarrays (Fig. 2A, B and C).

\section{NanoString nCounter profiling reveals downregulated miRNAs during metastatic spread of small bowel NETs}

Next, we compared the miRNA profiles of the LN metastases to their primary SBNETs for both profiling experiments. The 1st profiling revealed upregulation of four miRNAs (miR-142-3p, miR-146a-5p, miR-150-5p and miR-548) and downregulation of four miRNAs in the infiltrated LNs (miR-1, miR-133a, miR-145-5p and miR-1233; Supplementary Table 2 ). The 2 nd profiling discovered a further 4 miRNAs upregulated and 19 downregulated in LN metastases versus SBNETs (Supplementary Table 2). We observed that in both profiling results, four miRNAs were consistently downregulated in LN metastases (miR-1, miR-133a, miR-145-5p and miR-1233; central green intersection in Fig. 3) and also that miR-143-3p was highly downregulated in the 2nd profiling ( $\log 2 \mathrm{FC}-2.2$; Supplementary Table 2).

Next, we examined the differential expression of miRNAs in liver metastases compared with primary SBNETs (Supplementary Table 2). This revealed five upregulated and seven downregulated miRNAs in the liver metastases (all $\log 2$ FC $\leq 1.5$ or $\geq 1.5$; adjusted $P<0.05$; Supplementary Table 2). When combining these data with the profiles

Published by Bioscientifica Ltd 
Table 2 Most significantly deregulated miRNAs in lymph node metastases vs SBNETs.

\section{Deregulated miRNA}

(1st profiling)

miR-142-3p

miR-146a-5p

miR-150-5p

$\operatorname{miR}-548$

miR-145-5p $p^{b, c}$

miR-1233

miR-1c

miR-133ab,c

\begin{tabular}{|c|c|}
\hline Log2 fold-change & ${ }^{\text {aAdjusted } P \text { value }}$ \\
\hline 1.0 & $3.69 \mathrm{E}-05$ \\
\hline 0.9 & 0.00034256 \\
\hline 0.8 & 0.000324898 \\
\hline 0.5 & 0.006746057 \\
\hline-0.7 & 0.018028326 \\
\hline-0.8 & 0.00034256 \\
\hline-0.8 & 0.000412601 \\
\hline-1.0 & 5.75E-05 \\
\hline
\end{tabular}

Deregulated miRNA

(2nd profiling)

miR-15b-5p

miR-330-5p

miR-764

miR-191-5p

miR-1825c

miR-331-5p

miR-152

miR-574-5p

$\operatorname{miR}-28-3 p^{c}$

$\operatorname{miR}-28-5 p^{c}$

miR-9-5p

miR-30a-5pc

miR-10a-5p

miR-378gc

$\mathrm{miR}-378 \mathrm{a} / \mathrm{ic}$

miR-187-3p

miR-1233c

miR-139-5pc

miR-139-3pc

miR-145-5pb,c

miR-143-3pc

miR-133ab,c

miR-1c
Log2 fold-change

0.7

0.7

0.6

0.5

$-0.5$

$-0.7$

$-0.9$

$-0.9$

$-0.9$

$-1.0$

$-1.0$

$-1.1$

$-1.2$

$-1.5$

$-1.6$

$-1.6$

$-1.8$

$-1.9$

$-2.0$

$-2.1$

$-2.2$

$-2.9$

$-2.9$
aAdjusted $\boldsymbol{P}$ value

0.0143562

0.04581073

0.04581073

0.04581073

0.04792938

0.0143562

0.0293522

0.0143562

0.00142885

0.00077043

0.04470614

0.00142885

0.00142885

0.00010242

2.24E-05

2.43E-06

9.04E-07

4.45E-07

9.71E-08

1.87E-08

8.11E-09

5.25E-13

4.03E-14

Key: a $P$ value adjusted using false discovery rate (FDR) method. miRNAs included were $P<0.05$; ${ }^{b}$ Comparable to our data, these miRNAs were found to be downregulated in LN/liver metastases vs primary SBNETs in the study by Ruebel and coworkers (2010); cThese miRNAs are also deregulated in liver metastases vs SBNETs; dThese miRNAs were validated by qRT-PCR. miRNAs highlighted in gray were deregulated in both profiling experiments.

from the infiltrated LNs, we found significant overlap of 14 downregulated miRNAs in both types of metastases (green intersections in Fig. 3). Interestingly, these included reduced levels of miR-1, miR-133a, miR-143-3p, miR-145-5p and miR-1233. As miR-133a and miR-145-5p were previously found to be downregulated in metastases from SBNETs (Ruebel et al. 2010, Li et al. 2013b), we chose to focus on miR-1 and miR-143-3p. We confirmed by qRT-PCR that they are significantly downregulated in LN metastases versus primary SBNETs (Fig. 2D and E). Unfortunately, there was insufficient RNA from the liver metastases to perform further qRT-PCR.
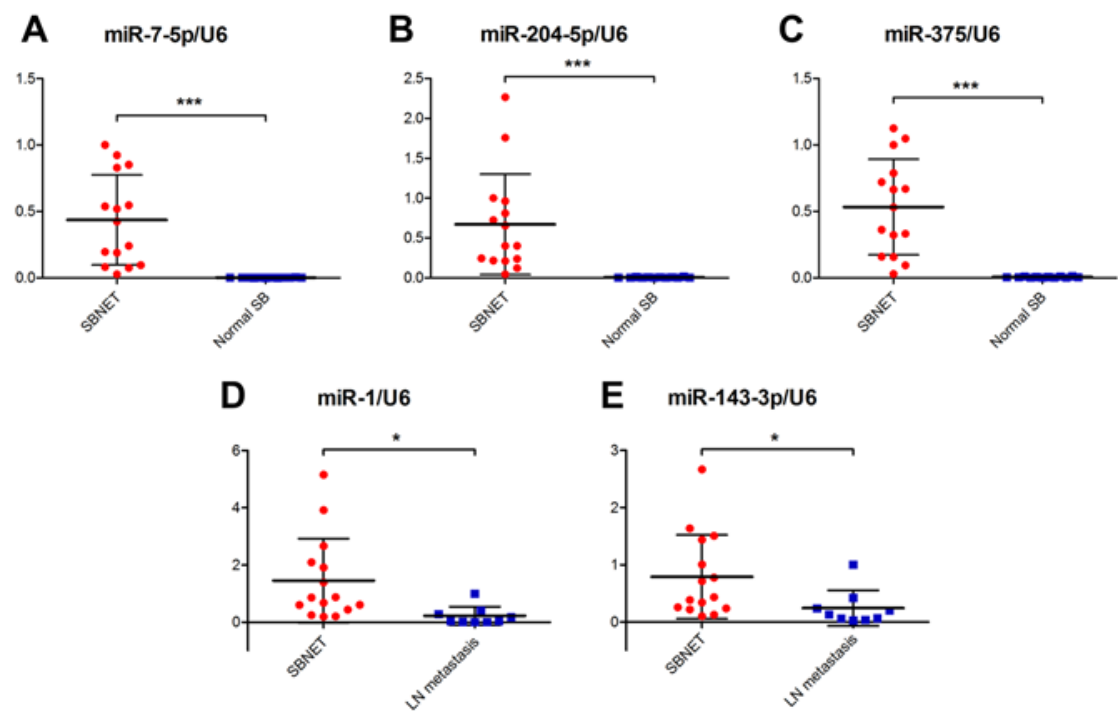

E $\quad \mathrm{miR}-143-3 \mathrm{p} / \mathrm{U} 6$

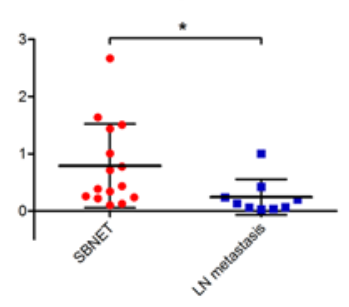

Figure 2

Deregulated miRNAs in SBNETs and their lymph node metastases were validated by qRT-PCR. We confirmed upregulation of (A) miR-7-5p; (B) miR-204-5p and (C) miR-375 in SBNETs versus adjacent normal small bowel (NSB). We also confirmed downregulation of (D) miR-1 and (E) miR-143-3p in lymph node (LN) metastases versus primary SBNETs. Small nucleolar U6 was used as an endogenous control. Results are presented as mean \pm s.D. $\left({ }^{*} P<0.05 ; * * * P<0.0001\right)$. A full colour version of this figure is available at http://dx.doi.org/10.1530/ERC-16-0044. 


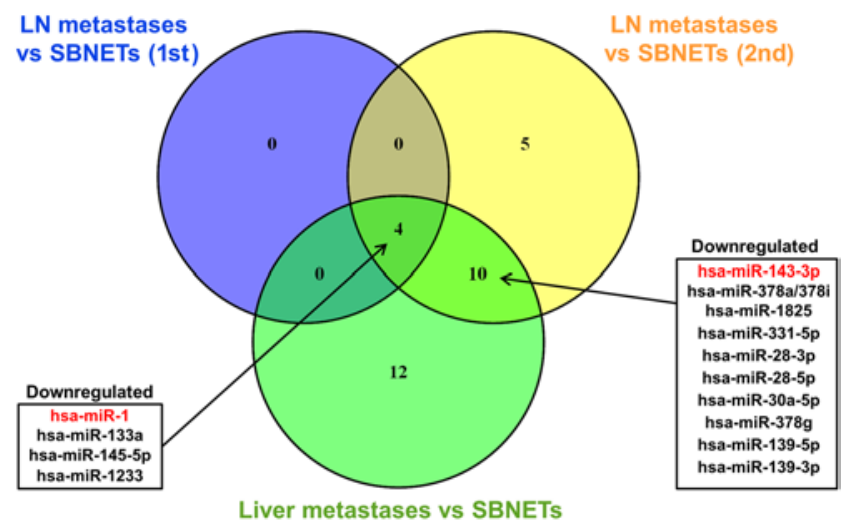

Figure 3

Venn diagram showing downregulated miRNAs in lymph node (LN) and liver metastases compared to their primary SBNETs. Four miRNAs (miR-1, miR-133a, miR145-5p and miR-1233) were found to be significantly downregulated in both LN and liver metastases versus their primary SBNETs (adjusted $P<0.05$ ). Furthermore, miR-143-3p was found to be downregulated in LN metastases (2nd profiling) and liver metastases versus normal tissues. Interestingly, our bioinformatic analyses revealed that miR-1 and miR-143-3p share many important gene targets of disease progression. A full colour version of this figure is available at http://dx.doi.org/10.1530/ERC-16-0044.

\section{microRNAs appear deregulated in liver metastases from SBNETs}

Next, we further examined the miRNA expression levels in the liver metastases and normal adjacent liver, as patients with SBNETs commonly develop this type of metastasis (Supplementary Table 2). Interestingly, as mentioned earlier, we found a subset of miRNAs significantly upregulated in the primary SBNETs, as well as the LN and liver metastases, compared with the corresponding normal tissues (Supplementary Table 2; central green intersection in Fig. 1B). However, there were also 17 miRNAs upregulated in the LN and liver metastases that were not upregulated in the primary SBNETs (light green intersection in Fig. 1B). Strikingly, we also observed that many of the miRNAs deregulated in liver metastases from normal liver could be located in clusters from the same primary transcript, suggesting transcriptional regulation. Furthermore, since the probes used by the nCounter profile assay are randomly located in the platform, we regard this as further validation of our findings (Supplementary Table 2). For example, amongst the miRNAs that we found to be upregulated, miR-141-3p, miR-200a-3p, miR-200b-3p and miR-200c-3p are all miR-200 family members and cluster together in particular genomic loci (green intersections in Fig. 1B; Supplementary Table 2).

Given their importance in cancer, we next investigated changes in the miR-200 family members in detail for the two patients for whom we had nCounter profiling of their adjacent normal liver and liver metastases (Supplementary Table 1). The miRNA200 family is known to be important in epithelial-tomesenchymal transition (EMT) and cancer progression (Craene \& Berx 2013). In the patient case studies, it is clear that miR-200 family members are upregulated in LN and liver metastases, compared with the primary SBNETs and normal tissues (Supplementary Fig. 3A and B). Interestingly, for Patient 9 (T3N1M1), levels of miR-200c-3p were the most prominent in the primary tumour, and the LN and liver metastases (Supplementary Fig. 3A). Whilst for Patient 2 (T4N1M1), all miR-200 family members were elevated during metastatic dissemination, with much higher levels in the LN metastases compared with Patient 9 (Supplementary Fig. 3B). Whilst these tumours are both stage IV, this difference in miR-200 family expression may be associated with advancing T-stage, since a $\mathrm{T}_{3}$ tumour has invaded the subserosa, whilst a $\mathrm{T}_{4}$ tumour has gone on to invade the peritoneum and/or other organs. Nevertheless, these findings suggest that a reversal of EMT or mesenchymal-toepithelial transition (MET) could be occurring in SBNET metastases and enforcing colonisation of distant organs. Furthermore, our case studies highlighted that in matched tissues, there appears to be a reduction in both miR- 1 and miR-143-3p levels during disease progression and metastasis, compared with the originating NSB mucosae and primary SBNETs (Supplementary Fig. 4A, B, C and D).

Finally, miR-122-5p emerged as downregulated in liver metastases vs normal adjacent liver $(\log 2$ FC -6.8; Supplementary Table 2). Its expression was not found to be significantly deregulated in either primary SBNET or LN metastases compared with normal tissues, but it was upregulated in liver metastases compared with SBNETs and LN metastases (log2 FC 3.7 and 1.7, respectively; Supplementary Fig. 2 and Table 2).

\section{miR-1 and miR-143 are found to target genes crucial in the progression of small bowel NETs including NUAK2 and FOSB oncogenes}

Next, we characterised the functional significance of the differentially expressed miRNAs in primary SBNETs and their LN metastases by evaluating their putative gene targets. To do this, we cross-checked the predicted targets with three publically available gene expression datasets previously assessing SBNETs vs NSB (GSE9576, GSE6272 and E-TABM-389) and the one available dataset comparing gene expression in SBNETs vs matched

Published by Bioscientifica Ltd 
LN metastases. We considered potential target genes to have expression opposite to that of the miRNA, in accordance to the antiregulation paradigm (i.e. upregulated miRNA and downregulated mRNA) (Frampton et al. 2014). We also performed enrichment analyses of gene ontology (GO) terms and Kyoto Encyclopedia of Genes and Genomes (KEGG) pathways, using DAVID (http://david. abcc.ncifcrf.gov) to help unravel the function of these deregulated miRNAs (Leja et al. 2009, Edfeldt et al. 2011, Kidd et al. 2014). In order to have more robust results when doing this enrichment analysis, we considered genes that appeared in $\geq 2$ expression datasets where possible, as well as being predicted targets of the miRNA of interest.

First, we considered those miRNAs highly expressed in SBNETs (i.e. miR-7, miR-204 and miR-375). Unfortunately, no significantly enriched GO terms or pathways were identified for the targets of these upregulated miRNAs, than would be obtained for randomly picked miRNAs (Supplementary Table 3) (Bleazard et al. 2015). Next, we considered miR-1 and miR-143, as they were downregulated in LN and liver metastases compared with SBNETs in the nCounter profiling, although not differentially expressed compared with normal tissues (Supplementary Table 2). This suggests that specific transcriptional networks in the primary tumour cells have changed during the metastasis of these cells. To further test this hypothesis, we analysed the genes upregulated, upon downregulation of miR-1 and miR-143 to assess their potential biological functions (Supplementary Table 4).

For miR-1, we found significant enrichment of GO terms relevant to tumour progression and a metastatic phenotype, such as GO:0042981 'regulation of apoptosis' (Benjamini-Hochberg $P=0.011$ ), GO:0043067 'regulation of programmed cell death' (Benjamini-Hochberg $P=0.008$ ) and GO:0010941 'regulation of cell death' (BenjaminiHochberg $P=0.006)$. Strikingly, the exact same GO terms were enriched for miR-143, GO:0042981 'regulation of apoptosis' (Benjamini-Hochberg $P=0.049$ ), GO:0043067 'regulation of programmed cell death' (BenjaminiHochberg $P=0.033$ ) and GO:0010941 'regulation of cell death' (Benjamini-Hochberg $P=0.025$ ). Target genes encompassed by these GO terms for both miRNAs included those normally upregulated in oncogenesis, such as NUAK2 (Namiki et al. 2011), EGFR (copy number gain seen in 4\% SBNETs (Banck et al. 2013)), KRAS, NRAS, IGF1 (Svejda et al. 2011, Reidy-Lagunes et al. 2012), MAPK1 (ERK1) (Svejda et al. 2011), BCL2, ARHGEF7 and BMP7 (Supplementary Table 4). Target genes specific only for miR-1 included HGF (Svejda et al. 2013) and $V E G F A$. These data suggest that downregulation of these two miRNAs could be key in the development of SBNET metastases through reduced repression of these genes and increased cancer cell survival. Accordingly, we validated a few of these target genes using the dataset GSE27162
A

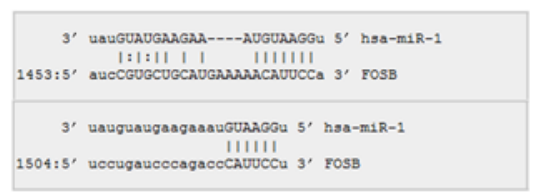

B

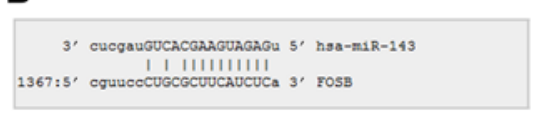

C

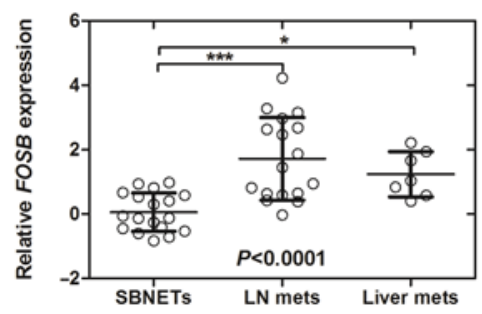

D

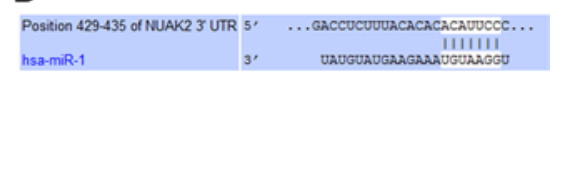

E

cucGavgucac--gahguagagu 5' hag-m1R-143 983:5. CuGCUGU-GUGGacUUCAUCUCA 3, NURK2

$\mathbf{F}$

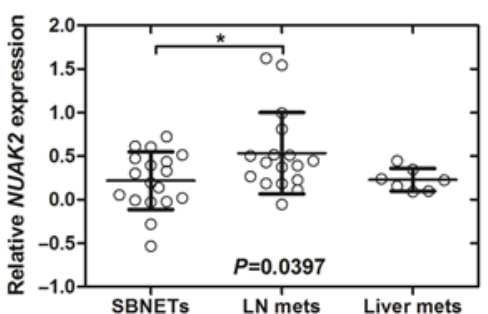

Figure 4

Reduction in miR-1 and miR-143 levels allows release of important oncogenes during SBNET progression. Using the miRanda-mirSVR target prediction algorithm, we identified (A) miR-1 and (B) miR-143 both target FOSB. Furthermore, assessing a publically available dataset of gene profiling (GSE27162), we found that (C) FOSB expression is increased in lymph node $(L N ; n=17)$ and liver metastases $(n=7)$ compared to primary SBNETs $(n=18)$. Similarly, using miRanda-mirSVR and TargetScan prediction algorithms, we found that (D) miR-1 and (E) miR-143 both regulate NUAK2. (F) NUAK2 expression is also increased in LN metastases compared to primary SBNETs. These data suggest that the reduction in miR-1 and miR-143 in metastases from SBNETs may allow reduced repression of important oncogenes FOSB and NUAK2, and therefore contribute to disease progression. $P$ values were calculated using one-way analysis of variance (ANOVA) to compare gene levels between groups followed by Tukey's multiple comparison tests. Scatterplots are shown for each group and the horizontal lines represent the mean gene expression level and S.D. $(* P<0.05, * * * P<0.001)$. A full colour version of this figure is available at http://dx.doi. org/10.1530/ERC-16-0044. 
A

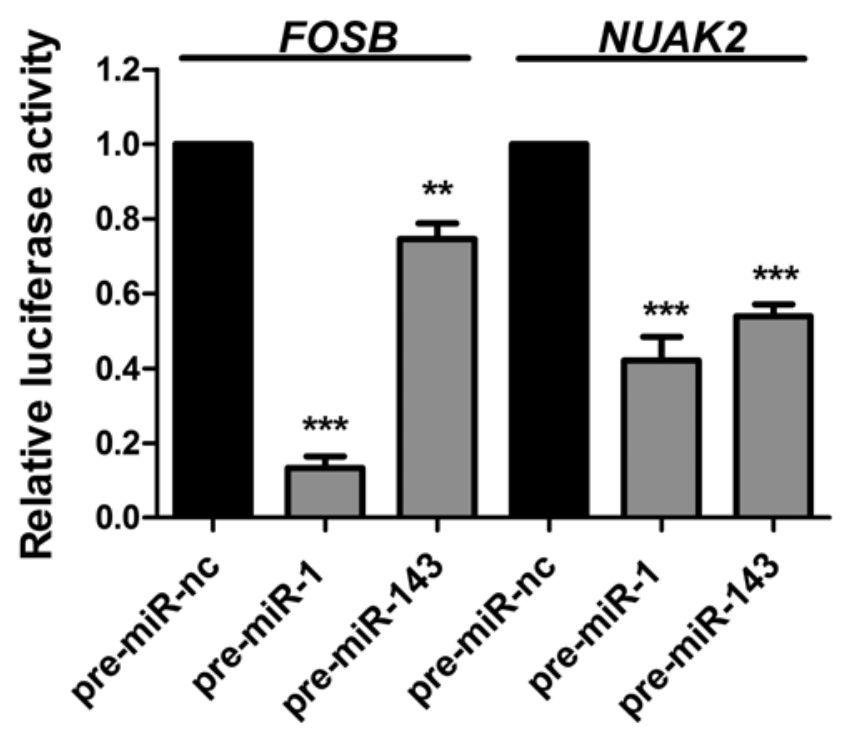

B

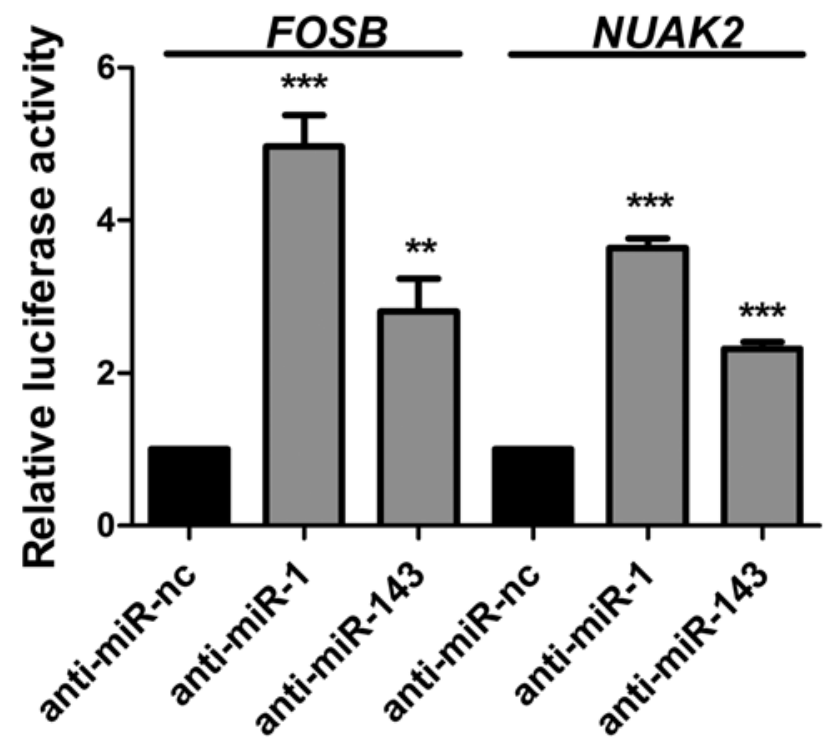

Figure 5

FOSB and NUAK2 oncogenes are directly targeted by miR-1 and miR-143. HEK293T cells were cotransfected with (A) precursor microRNA negative control mimic (pre-miR-nc) or precursors to miR-1 or miR-143 (100 nM), or (B) anti-microRNA negative control (anti-miR-nc) or anti-miR-1 or anti-miR-143 (100 nM), together with FOSB or NUAK2 3'UTR reporter constructs (100 ng/well). Luciferase activity was measured 24 -h posttransfection. Horizontal lines represent the mean luciferase activity and S.E.M. from independent experiments, each measured in triplicate $(* * P<0.01, * * * P<0.001)$

and found that KRAS and BCL2 were upregulated in LN metastases vs primary SBNETs (Supplementary Fig. 5A and B), while HGF and VEGFA were upregulated in both LN and liver metastases vs primary SBNETs (Supplementary Fig. 6A and B).

Furthermore, when assessing individual putative gene targets for these miRNAs that were differentially expressed in the dataset GSE27162, we noticed an important interaction that could be related to SBNET progression. Our bioinformatic analyses revealed that both miR-1 and miR-143 are predicted to target NUAK2 and FOSB, and these genes are significantly upregulated in SBNET LN metastases, more so than in hepatic disease, compared with primary SBNETs (Fig. 4A, B, C, D, E and F). Next, we investigated the direct binding of miR-1 and miR-143 to the seed sequences in the 3 '-untranslated regions (UTRs) of NUAK2 and FOSB. We used 3'-UTR constructs for each gene in a $3^{\prime}$-UTR luciferase reporter assay (SwitchGear Genomics, Menlo Park, CA, USA) to prove that these genes are miRNA targets. Indeed, cotransfection of HEK293T cells with precursors for miR-1 or miR-143 resulted in significant reduction in luciferase activity compared with the negative control precursors for both FOSB and NUAK2 oncogenes (Fig. 5A). Conversely, transfection with anti-miRs for miR-1 and miR-143 significantly increased luciferase activity compared with negative controls for both FOSB and NUAK2 (Fig. 5B), demonstrating that both miRNAs target these genes. Next, we tried to confirm these results using KRJ-I cells (neoplastic enterochromaffin cells) derived from a localised human ileal carcinoid (Pfragner et al. 1996). However, over-expression or silencing of both miR-1 and miR-143 in KRJ-I cells (Supplementary Fig. 7) did not show any changes in FOSB and NUAK2 transcript or protein expression (Supplementary Fig. 8), indicating that these miRNA-mRNA interactions probably occur in selected subtypes or metastatic SBNET cells. Whilst KRJ-I cells have been used as a model for the in vitro investigation of SBNETs, it may be that other cells, especially those derived from metastatic disease, would have been better models for examining these miRNA-mRNA interactions. Unfortunately, we did not have access to other SBNET cells, such as P-STS (derived from primary tumour), L-STS (from LN metastasis), H-STS (from liver metastasis) or CNDT2 (from liver metastasis) to validate these miRNA-mRNA interactions (Van Buren et al. 2007, Pfragner et al. 2009).

\section{Discussion}

Current staging and grading systems used to classify SBNETs have attempted to stratify tumours, in order to predict survival outcomes and the risk of developing metastatic disease, but can often be ineffective.

Published by Bioscientifica Ltd 
Consequently, novel molecular biomarkers are required to aid diagnosis, prognosis and the development of targeted therapies. The current study represents the most extensive assessment of miRNA profiling in SBNETs and their metastases. We also gained some insight into changes in miRNA expression in patients with matched liver metastases. We identified miRNA-mRNA interactions, which could have a key role in disease progression in SBNET. Important hypotheses have been generated from these data that will provide the basis for further investigations.

\section{Global miRNA profiling reveals a signature specific for small bowel NETs}

Our strategy consisted of identifying differentially expressed miRNAs in SBNETs vs adjacent NSB tissues, and then assessing changes in miRNA expression between SBNETs and their LN and liver metastases. We selected 90 patient samples (primary tumours, metastases and normal tissues) for miRNA profiling. From the global miRNA profiling, we identified an miRNA signature for SBNETs compared with NSB tissues, consisting of 38 upregulated miRNAs and 1 downregulated miRNA (Supplementary Table 2; intersection in Fig. 1A; Supplementary Fig. 1A). Next, we confirmed the upregulation of miR-204-5p, miR-7-5p and miR-375 by qRT-PCR to validate our SBNET miRNA signature and profiling methods (Fig. 2A, B and C). Interestingly, previous profiling by $\mathrm{Li}$ and coworkers (Li et al. 2013b) found significant altered expression in miR-31, miR-96, miR-129-5p, miR-182, miR-196a, miR200a and miR-215 in SBNETs and our findings were consistent with this (Table 1). We also found that miR133a and miR-145-5p, as well as others, were significantly downregulated in LN metastases compared with SBNETs (Fig. 3 and Table 2), in keeping with findings of a previous smaller profiling study assessing only 95 miRNAs (Ruebel et al. 2010). This suggests that these miRNAs could be reliable for detecting SBNETs in other patient cohorts also, especially since we identified these in both profiling experiments (Fig. 3 and Table 2). Furthermore, we also found novel miRNAs deregulated in SBNETs (Fig. 1; Supplementary Fig. 1) and, importantly, also in their associated LN and liver metastases (Fig. 3; Supplementary Fig. 2) that have not been previously considered in this tumour type.

Interestingly miR-7 was upregulated in our SBNETs (Fig. 1B and Table 1; Supplementary Table 2), in contrast to other cancers where it has been identified as downregulated, functioning as a tumour suppressor. Indeed, reduced miR-7 levels are seen in highly invasive breast cancer stem cells (Zhang et al. 2014), metastatic gastric cancer (Zhao et al. 2013), colorectal cancer (Xu et al. 2014) and pancreatic cancer (Ma et al. 2014). Recently, a circular RNA, ciRS-7, has been identified to act as an endogenous miR-7 inhibitor/sponge (Hansen et al. 2013). Thus, ciRS-7 expression results in reduced miR-7 activity and consequently increased levels of miR-7 target transcripts, since it harbours more than 70 binding sites for miR-7 (Hansen et al. 2013). However, miR-7 has also been shown to have oncogenic properties and, therefore, is tissue-specific (Chou et al. 2010). In lung cancer, EGFR is able to induce miR-7 expression through a Ras/ERK/Myc pathway (Chou et al. 2010). Over-expression of miR-7 in vitro promotes lung cancer cell growth and increases the mortality of nude mice with orthotopically implanted lung tumours (Chou et al. 2010). Thus, the role and mechanism of miR-7 in SBNETs merits further investigation, and it would also be important to evaluate ciRS-7 expression. Similarly, whilst we found upregulation of miR-204 in SBNETs, it has been seen as downregulated in gastric cancer (Sacconi et al. 2012, Zhang et al. 2013), colorectal cancer (Yin et al. 2014) and clear cell renal cell carcinoma (Mikhaylova et al. 2012). Thus, its increased expression and role in SBNETs remains unknown. We found elevated miR-375 levels in SBNETs, which is also more often downregulated in cancers. However, high expression of miR-375 has been seen in ER $\alpha$-positive breast cell lines and it is a key driver of their proliferation (de Souza Rocha Simonini et al. 2010).

There were fewer miRNAs significantly downregulated in SBNETs compared with adjacent NSB (Table 1; Supplementary Fig. 1A and Table 2). Of these, miR-215 was downregulated in the 1st profiling of SBNETs vs NSB (Table 1). miR-215 is also reduced in metastatic renal cell carcinomas and over-expression is able to decrease cell migration and invasion in vitro (White et al. 2011). Interestingly, miR-215 functions as a tumour suppressor with its activation inducing cell cycle arrest in a p53dependent manner (Georges et al. 2008). We also found that miR-31-5p (miR-31) was significantly downregulated in SBNETs compared with NSB mucosae in both profiling experiments (Supplementary Fig. 1B and Table 2). The study by $\mathrm{Li}$ and coworkers also identified miR-215 and miR-31 as downregulated in SBNETs compared with normal enterochromaffin (EC) cells, with further downregulation in $\mathrm{LN}$ and liver metastases compared with the primary tumours (Li et al. 2013b). Indeed, miR-31 has been shown to be a tumour suppressor with antimetastatic properties in breast and liver cancers (Viré et al. 2014, Kim et al. 2015). We, however, did not see any

Published by Bioscientifica Ltd. 
reduction in the levels of miR-31 and miR-215 in SBNET metastases (Supplementary Table 2).

\section{miR-1 and miR-143 are downregulated during metastatic spread to regional lymph nodes and the liver}

Next, we examined miRNAs deregulated in SBNET metastases. We identified that miR-1 and miR-143-3p (miR-143) are significantly downregulated in LN and liver metastases compared with the primary SBNETs (Figs 2D, $\mathrm{E}$ and 3). However, these miRNAs were not differentially expressed compared with normal LNs (Supplementary Table 2). This suggests that loss of expression may be associated with the development of metastases, especially since the majority of the SBNETs profiled were LN positive (N1) and developed liver deposits. Further assessment of miR-1 and miR-143 in SBNETs that did not develop metastases is now warranted to see if primary tumours with lower levels of these miRNAs are more likely to metastasise.

Indeed, looking at our two case studies, we realised that from NSB tissue to SBNET, to LN infiltration and finally liver metastasis, there appears to be a gradual reduction in both miR-1 and miR-143 expression (Supplementary Fig. 4A, B, C and D). Whilst the levels of these miRNAs do not appear to be altered from normal LN and liver, their biological relevance in the infiltrating cancerous cells originating from matched primary tumours is still of importance.

To further explore the possible functional consequences of the downregulation of these miRNAs, we performed gene- and pathway-enrichment analyses on putative targets and publically available gene expression datasets. Strikingly, we found that both miRNAs affect genes involved in the regulation of apoptosis and this could help to explain their role in SBNET progression (Supplementary Table 4). Our bioinformatic analyses also revealed that both $\mathrm{miR}-1$ and $\mathrm{miR}-143$ are predicted to target $F O S B$, and this gene is significantly upregulated in LN and liver metastases versus primary SBNETs (GSE27162; Fig. 4C). Indeed, we show that miR-1 and miR-143 both directly bind to the $3^{\prime}$ UTR of FOSB (Fig. 5). Interestingly, FOSB transcription is induced by metastasisassociated protein 1 (MTA1), and consequently represses E-cadherin expression in TGF- $\beta 1$-stimulated breast cancer cells (Pakala et al. 2011). Thus, the miR-1/FOSB and miR-143/FOSB axes may be able to regulate EMT and, therefore, metastasis in SBNETs also. Furthermore, it has been shown in KRJ-I (neoplastic EC) cells that
TGF- $\beta 1$ stimulation results in increased cell proliferation (Kidd et al. 2007). However, this is not due to classical SMAD signalling, but rather upregulation of $c-M Y C$, concomitant activation of $c-M Y C$ transcriptional targets and inhibition of $p 21^{\text {WAF1/CIP }}$ (Kidd et al. 2007). In addition, TGF- $\beta 1$ stimulation increases the expression of MTA1 transcript and decreases E-cadherin expression in KRJ-I cells (Kidd et al. 2007). MTA1 has also been shown to be over-expressed in malignant primary SBNETs and their metastases (Kidd et al. 2006, 2007). Therefore, reduced post-transcriptional repression of FOSB, by downregulation of miR-1 and miR-143, could potentiate invasion and metastasis caused by the TGF $\beta 1$-pathway via MTA1 in SBNET cells.

miR-1 and miR-143 have both been noted as downregulated in numerous tumour types. miR-1 is reduced in primary prostate cancer compared with normal tissue, and levels are further decreased in metastatic disease (Liu et al. 2015). Indeed, in aggressive prostate cancer mouse models, loss of miR-1 enhances mesenchymal commitment, invasiveness and tumourigenesis (Liu et al. 2013). Accordingly, re-expression of miR-1 in bladder cancer (Yoshino et al. 2011), hepatocellular carcinoma (Datta et al. 2008), lung cancer (Nasser et al. 2008) and rhabdomyosarcoma (Yan et al. 2009) inhibits tumour cell growth and metastatic traits. Deep sequencing has also found miR-1 levels to be reduced in colorectal cancers (CRCs) and a case of colorectal NET (Hamfjord et al. 2012). miR-1 downregulation in human CRCs has been correlated with over-expression of the MET gene, especially in advanced stages of progression (Migliore et al. 2012). The MET oncogene encodes a tyrosine kinase receptor that binds hepatocyte growth factor (HGF) and drives the malignant progression of several tumour types (Reid et al. 2012). Experiments in CRC cells have confirmed the tumour-suppressive ability of miR-1, as enforced expression impairs cell scattering, migration, wound-healing and proliferation in response to HGF (Migliore et al. 2012). Thus, activation of MET, due to a decrease in miR-1 is likely to be associated to cancer progression and to the acquisition of an invasive phenotype and metastatic dissemination (Migliore et al. 2012, Reid et al. 2012). Interestingly, our bioinformatic analyses revealed $H G F$ to also be targeted by miR-1 and we found $H G F$ levels significantly increased in LN and liver metastases compared with primary SBNETs (Supplementary Fig. 6A). However, we could not see an increase in MET expression between primary SBNETs and metastases (GSE27162; data not shown). 
Nevertheless, MET proto-oncogene over-expression has been correlated with metastaticabilityin well-differentiated PNETs (Hansel et al. 2004), and further investigation in a larger cohort of SBNETs is warranted. We also noticed that miR-1 targets VEGFA, and found VEGFA levels are indeed significantly higher in LN and liver metastases compared with primary SBNETs (Supplementary Fig. 6B). This is very relevant to SBNET biology, as these tumours are highly vascular, and currently there are several clinical trials investigating VEGF signalling as a prime therapeutic target. Importantly, recent whole-exome sequencing has shown that VEGFA is not mutated in SBNETs (Banck et al. 2013); thus, loss of post-transcriptional regulation by miR-1 in SBNET metastases could explain higher levels of transcript in these lesions.

Reduced miR-1 expression is also thought to play an oncogenic role via release of specific target genes such as LASP1, IGF1, IGF1R or BCL2 (antiapoptotic gene) in CRC (Migliore et al. 2012). IGF1R is highly expressed in a large percentage of primary SBNETs (46\%), LN metastases (50\%) and liver metastases (68\%) (Gilbert et al. 2010). Thus, the miR-1/IGF1R interaction should be further validated. Furthermore, we identified BCL2 as upregulated in $\mathrm{LN}$ metastases compared with primary SBNETs, and it is not only targeted by miR-1, but also by miR-143 (Supplementary Fig. 5B). These novel interactions, miR-1/BCL2 and miR-143/BCL2, deserve further investigation. Finally, we also revealed that miR-1 and miR-143 target NUAK2, which has been shown to be oncogenic in melanoma (Namiki et al. 2015) and gastric cancer (Kim et al. 2013), and levels of this transcript were also upregulated in LN metastases compared with SBNETs (Fig. 4F). Importantly, we also show that miR-1 and miR-143 both directly target the 3'UTR of NUAK2 (Fig. 5).

miR-143 has been shown to have an antimetastatic effect and is downregulated in several cancers (Takagi et al. 2009, Kent et al. 2010, Peng et al. 2011). miR-143 and miR-145 are often cotranscribed and are usually investigated together as tumour suppressors (Kent et al. 2014). In prostate cancer, over-expression of miR-143 and -145 reduces migration and invasion in vitro and tumour development and bone invasion in vivo (Peng et al. 2011). Furthermore, lower expression of miR-143 and miR-145 in primary prostate cancers was significantly associated with tumour progression and the development of bone metastases (Peng et al. 2011). Interestingly, deregulation of miR-143 and miR-145 has not been seen in LN metastasis compared with primary prostate tumours (Spahn et al. 2010). This suggests that in prostate cancer, the functional loss of miR-143 or miR-145 may be cell-type-specific and results in bone metastasis, instead of LN metastasis (Peng et al. 2011). Reduced miR-143 expression also plays a crucial role in the invasion and metastasis of pancreatic cancer (Hu et al. 2012). In a metastatic mouse model of pancreatic cancer, miR-143 expression significantly reduced the formation of liver metastases (Hu et al. 2012). Furthermore, xenograft pancreatic tumour growth was reduced by miR-143 through downregulating ARHGEF1, ARHGEF2 and KRAS, and reducing MMP-2 and MMP-9 protein levels, whilst increasing E-cadherin protein levels (Hu et al. 2012). Importantly, putative interactions exist between miR-1/MMP-8 and miR-1/KRAS, and miR143/KRAS and miR-143/MMP-19 (Supplementary Figs 5A and $9 \mathrm{~A}, \mathrm{~B}, \mathrm{C}, \mathrm{D})$. Indeed, our bioinformatic analyses revealed that KRAS, MMP-8 and MMP-19 are upregulated in LN metastases vs SBNETs (GSE27162; Supplementary Figs 5A and 9A, B, C, D). These miRNA-mRNA interactions deserve validation in vitro and in vivo. Our analyses showed that there is an increase in the KRAS transcript during SBNET progression (GSE27162; Supplementary Fig. 5A); however, recent deep sequencing has shown that KRAS is not actively mutated in SBNETs (Banck et al. 2013). This suggests that there may be post-transcriptional regulation occurring by loss of miR-1 and miR-143, thereby allowing an increase in KRAS.

\section{Reduction in miR-122 may play a role in small bowel NET progression and act as a biomarker for liver metastases}

miR-122-5p appeared strongly downregulated in liver metastases versus adjacent normal liver (Supplementary Fig. 1B and Table 2), although still significantly upregulated in liver metastases vs SBNETs (Supplementary Fig. 2 and Table 2). Indeed, miR-122 is known to be highly expressed in the liver $(\sim 70 \%$ of all miRNA content in liver) and is tissue-specific (Jopling 2012). Furthermore, miR-122 levels are frequently reduced in hepatocellular carcinoma (HCC) compared with normal liver, and lower miR-122 expression is associated with worse prognosis (Jopling 2012). miRNA-122 expression has been found to be regulated by DNA methylation and correlates with apoptosis in HCC cells (Xing et al. 2013). Thus, in HCC, miR-122 acts as a tumour suppressor, and its loss correlates with gain of metastatic properties and suppression of the hepatic phenotype (Coulouarn et al. 2009). Interestingly, in CRC liver metastases, miR-122 levels are higher compared with primary CRCs and/or normal colonic mucosae (Iino et al. 2013, Ellermeier et al . 2014). Possible reasons for this include either detecting residual liver tissue within the CRC liver metastases,

Published by Bioscientifica Ltd. 
as primary CRCs have low miR-122 expression (Ellermeier et al. 2014), or that miR-122 is upregulated in CRC cells during the process of liver metastasis, rather than during carcinogenesis (Iino et al. 2013). Thus, following the proposed 'seed and soil' theory, during the formation of CRC liver metastasis, cancer cells try to adapt to their new environment by expressing miR-122, whilst HCC cells prepare to metastasise out of the liver by reducing miR-122 levels (Iino et al. 2013). Clearly, the role of miR-122 in cancer progression depends on the primary site. We speculate, therefore, that miR-122 may be a biomarker for SBNET liver metastases; however, further samples need to be assessed.

\section{miR-200 family members are deregulated in small bowel NET progression accompanying a reversal of epithelial- to-mesenchymal transition}

Several studies have shown that the TGF $\beta$ and EMT pathways contribute to tumour growth and metastasis in SBNETs. Indeed, E-cadherin expression is often reduced in SBNETs compared with NSB mucosae and has been correlated with malignant behaviour (Kawahara et al. 2002, Li et al. 2002). E-cadherin levels are also lower in larger $(>2 \mathrm{~cm})$ SBNETs and those with transmural invasion (Li et al. 2002). Furthermore, recent whole-exome sequencing has revealed that SMAD2 and SMAD4 genes are frequently deleted (Banck et al. 2013). However, we found significant upregulation of miR-200a-3p in SBNETs vs NSB (Fig. 1B; Supplementary Table 2), and this can be used as a surrogate for E-cadherin levels (Craene \& Berx 2013). Unexpectedly, we also noticed elevated levels of miR-200 family members in SBNET metastases compared with normal tissues (Fig. 1B), and consistent with this, when assessing previous gene profiling, we found stable or reverse expression of EMT markers (ZEB1/2, CDH1) in liver metastases compared with primary SBNETs (Supplementary Fig. 10A, B and C). Indeed, whilst SBNETs commonly metastasise to the liver, with the development of multiple lesions, these behave in a relatively indolent manner from an oncologic perspective (Reddy \& Clary 2010). Thus, a 'seed and soil' phenomenon may explain these findings that miR-200s appear to be elevated in SBNET metastases (Fig. 1B), allowing possible repression of ZEB1/2 and consequent stabilisation of E-cadherin ( $C D H 1)$ expression, thereby allowing colonisation of large parts of the liver. Interestingly, over-expression of miR-200s has also been shown to be pro-metastatic and promote metastatic colonisation in breast cancer by influencing not only E-cadherin-dependent epithelial traits, but also the Sec23a-mediated tumour cell secretome (Korpal et al. 2011). Thus, the exact role of miR-200s in SBNET liver metastases remains uncertain.

\section{Limitations}

We were unable to dissect out the differences in miRNA expression between different grades of SBNETs. However, this is not surprising since $90 \%$ of patients have G1 tumours and only 10\% have G2 lesions. Furthermore, we do not resect patients with G3 tumours, as they are extremely rare and usually go for chemotherapy and not surgical treatment (Clift et al. 2016). Therefore, it would be appropriate, but extremely difficult, for future studies to include a larger number of primary SBNETs in each grade. Similarly, it would be interesting, but almost impossible, to assess miRNA profiles in those with $\mathrm{N} 0$ vs $\mathrm{N} 1$, as nearly all patients have G1 tumours and 90\% are N1 (Clift et al. 2016). However, it would be possible and important to assess those primary SBNETs with and without liver metastases, as well as circulating miRNAs in such patients.

We had difficulty confirming NUAK2 and FOSB as direct targets of miR-1 and miR-143 in KRJ-I cells. Indeed, miRNA-mRNA interactions occur in a contextdependent, cell-type-specific manner (Kedde et al. 2007, Erhard et al. 2014), and we would have liked to investigate these in an additional SBNET cell line, but were unable to do so. However, we did validate these miRNA-mRNA interactions in HEK293T cells. Furthermore, these miRNAs are clearly downregulated in metastases vs primary SBNETs in patients in two independent miRNA profiling experiments (Fig. 3), whilst NUAK2 and FOSB are more expressed in LN metastases vs primary SBNETs (Fig. 4C and $\mathrm{F}$ ), suggesting that they are being regulated in vivo.

\section{Future work}

Further investigations will include validation of these miRNAs in larger cohorts of patient samples and correlation with clinicopathologic factors. We also plan to study miRNAs in blood samples and compare the results with those obtained from tumour tissues. This will enable us to examine miRNAs involved in disease progression and identify clinically useful biomarkers. The availability of serum from patients also raises the possibility of applying a liquid biopsy approach to SBNETs, potentially enabling the noninvasive early detection of micrometastases or treatment response monitoring using circulating-free miRNAs (Miller et al. 2015). Furthermore, work in vitro and in vivo using cell lines derived from SBNETs, and other models, will help

Published by Bioscientifica Ltd. 
to validate further key target genes of these miRNAs and phenotyping studies will elucidate the functions of these miRNAs in SBNETs (Pfragner et al. 1996).

\section{Conclusions}

We have identified novel miRNAs that may potentially differentiate between primary SBNETs and NSB, including the upregulation of miR-204-5p, miR-7-5p and miR-375. Our data also suggest that miRNAs could be used to further classify SBNETs according to their biological behaviour. Indeed, we show that miR-1 and miR-143-3p are downregulated in SBNET and their metastases, and that their target gene pathways are crucial for tumour development and disease progression. Additional experiments will help to define the mechanistic functions of these miRNAs and their potential use as biomarkers and/or therapeutic targets.

\section{Supplementary data}

This is linked to the online version of the paper at http://dx.doi.org/10.1530/ ERC-16-0044

\section{Declaration of interest}

The authors declare that there is no conflict of interest that could be perceived as prejudicing the impartiality of the research reported.

\section{Funding}

This study was supported by the Imperial Experimental Cancer Medicine Centre, Imperial NIHR Biomedical Research Centre, Cancer Research UK Imperial Centre and in part by grants from Action Against Cancer and the Dr Heinz-Horst Deichmann Foundation. A M holds a Research Fellow grant from the European Neuroendocrine Tumor Society (ENETS).

\section{Author contribution statement}

A F, L C and A E F were involved in study concept and design. H C M, L C, $R F, E A S, D K, O F, G H, A M$ and $S O$ were involved in acquisition of data. A E F, H C M, LC, E A S, R F, A M, S O, G S and R P were involved in analysis and interpretation of data. A E F, H C M, A F and $L C$ were involved in drafting of the manuscript. A E F, HCM, A F, J S, L C, D K, O F, G H, G S, R P and $B K$ were involved in Revision of manuscript. A F, L C, J S, R F, E A S and $\mathrm{B} \mathrm{K}$ were involved in supervision of work.

\section{Ethics approval}

This study is part of our project R12025: Genetic signature, metabolic phenotyping and integrative biology of neuroendocrine tumours. Ethics approval REC number: 07/MRE09/54.

\section{Acknowledgements}

Tissue samples were provided by the Imperial College Healthcare NHS Trust Tissue Bank and the Zentralklinik Bad Berka, Germany. Other investigators may have received samples from these same tissues. The research was supported by the National Institute for Health Research (NIHR) Biomedical Research Centre based at Imperial College Healthcare NHS Trust and Imperial College London. The views expressed are those of the authors and not necessarily those of the NHS, the NIHR or the Department of Health. This work forms part of the PhD thesis of Miss Helen C Miller. Raw profiling data has been deposited at GEO under accession number GSE70534 and can be accessed at: http://www.ncbi.nlm.nih.gov/geo/query/acc. cgi?acc=GSE70534

\section{References}

Ahmed A, Turner G, King B, Jones L, Culliford D, McCance D, Ardill J, Johnston BT, Poston G, Rees M, et al. 2009 Midgut neuroendocrine tumours with liver metastases: results of the UKINETS study. Endocrine-Related Cancer 16 885-894. (doi:10.1677/ERC-09-0042)

Banck MS, Kanwar R, Kulkarni AA, Boora GK, Metge F, Kipp BR, Zhang L, Thorland EC, Minn KT, Tentu R, et al. 2013 The genomic landscape of small intestine neuroendocrine tumors. Journal of Clinical Investigation 123 2502-2508. (doi:10.1172/ JCI67963)

Bleazard T, Lamb J \& Griffiths-Jones S 2015 Bias in microRNA functional enrichment analysis. Bioinformatics 31 1592-1598. (doi:10.1093/ bioinformatics/btv023)

Calin GA \& Croce CM 2006 MicroRNA signatures in human cancers. Nature Reviews Cancer 6 857-866. (doi:10.1038/nrc1997)

Chou Y-T, Lin H-H, Lien Y-C, Wang Y-H, Hong C-F, Kao Y-R, Lin S-C, Chang Y-C, Lin S-Y, Chen S-J, et al. 2010 EGFR promotes lung tumorigenesis by activating miR-7 through a Ras/ERK/Myc pathway that targets the Ets 2 transcriptional repressor ERF. Cancer Research 70 8822-8831. (doi:10.1158/0008-5472.CAN-10-0638)

Clift AK, Faiz O, Al-Nahhas A, Bockisch A, Liedke MO, Schloericke E, Wasan H, Martin J, Ziprin P, Moorthy K, et al. 2016 Role of staging in patients with small intestinal neuroendocrine tumours. Journal of Gastrointestinal Surgery 20 180-188. (doi:10.1007/s11605-015-2953-6)

Coulouarn C, Factor VM, Andersen JB, Durkin ME \& Thorgeirsson SS 2009 Loss of miR-122 expression in liver cancer correlates with suppression of the hepatic phenotype and gain of metastatic properties. Oncogene 28 3526-3536. (doi:10.1038/onc.2009.211)

Craene BD \& Berx G 2013 Regulatory networks defining EMT during cancer initiation and progression. Nature Reviews Cancer 13 97-110. (doi:10.1038/nrc3447)

Datta J, Kutay H, Nasser MW, Nuovo GJ, Wang B, Majumder S, Liu CG, Volinia S, Croce CM, Schmittgen TD, et al. 2008 Methylation mediated silencing of microRNA-1 gene and its role in hepatocellular carcinogenesis. Cancer Research 68 5049-5058. (doi:10.1158/00085472.CAN-07-6655)

de Souza Rocha Simonini P, Breiling A, Gupta N, Malekpour M, Youns M, Omranipour R, Malekpour F, Volinia S, Croce CM, Najmabadi H, et al. 2010 Epigenetically deregulated microRNA-375 is involved in a positive feedback loop with estrogen receptor $\alpha$ in breast cancer cells. Cancer Research 70 9175-9184. (doi:10.1158/00085472.CAN-10-1318)

Edfeldt K, Bjorklund P, Akerstrom G, Westin G, Hellman P \& Stalberg P 2011 Different gene expression profiles in metastasizing midgut carcinoid tumors. Endocrine-Related Cancer 18 479-489. (doi:10.1530/ ERC-10-0256)

Ellermeier C, Vang S, Cleveland K, Durand W, Resnick MB \& Brodsky AS 2014 Prognostic microRNA expression signature from examination of colorectal primary and metastatic tumors. Anticancer Research $\mathbf{3 4}$ 3957-3967.

Ellis L, Shale MJ \& Coleman MP 2010 Carcinoid tumors of the gastrointestinal tract: trends in incidence in England since 1971. American Journal of Gastroenterology 105 2563-2569. (doi:10.1038/ ajg.2010.341)

Published by Bioscientifica Ltd. 
Erhard F, Haas J, Lieber D, Malterer G, Jaskiewicz L, Zavolan M, Dolken L \& Zimmer R 2014 Widespread context dependency of microRNA-mediated regulation. Genome Research 24 906-919. (doi:10.1101/gr.166702.113)

Esquela-Kerscher A \& Slack FJ 2006 Oncomirs [mdash] microRNAs with a role in cancer. Nature Reviews Cancer 6 259-269. (doi:10.1038/ nrc1840)

Fraenkel M, Kim MK, Faggiano A \& Valk GD 2012 Epidemiology of gastroenteropancreatic neuroendocrine tumours. Best Practice \& Research Clinical Gastroenterology 26 691-703. (doi:10.1016/j. bpg.2013.01.006)

Frampton AE, Castellano L, Colombo T, Giovannetti E, Krell J, Jacob J, Pellegrino L, Roca-Alonso L, Funel N, Gall TM, et al. 2014 MicroRNAs cooperatively inhibit a network of tumor suppressor genes to promote pancreatic tumor growth and progression. Gastroenterology 146 268-277.e18. (doi:10.1053/j.gastro.2013.10.010)

Frilling A, Modlin IM, Kidd M, Russell C, Breitenstein S, Salem R, Kwekkeboom D, Lau WY, Klersy C, Vilgrain V, et al. 2014 Recommendations for management of patients with neuroendocrine liver metastases. Lancet Oncology 15 e8-e21. (doi:10.1016/s14702045(13)70362-0)

Georges SA, Biery MC, Kim S-Y, Schelter JM, Guo J, Chang AN Jackson AL, Carleton MO, Linsley PS, Cleary MA, et al. 2008 Coordinated regulation of cell cycle transcripts by p53-Inducible microRNAs, miR-192 and miR-215. Cancer Research 68 10105-10112. (doi:10.1158/0008-5472.CAN-08-1846)

Gilbert JA, Adhikari LJ, Lloyd RV, Rubin J, Haluska P, Carboni JM, Gottardis MM \& Ames MM 2010 Molecular markers for novel therapies in neuroendocrine (carcinoid) tumors. Endocrine-Related Cancer 17 623-636. (doi:10.1677/ERC-09-0318)

Hamfjord J, Stangeland AM, Hughes T, Skrede ML, Tveit KM, Ikdahl T \& Kure EH 2012 Differential expression of miRNAs in colorectal cancer: comparison of paired tumor tissue and adjacent normal mucosa using high-throughput sequencing. PLOS ONE 7 e34150. (doi:10.1371/journal.pone.0034150)

Hansel DE, Rahman A, House M, Ashfaq R, Berg K, Yeo CJ \& Maitra A 2004 Met proto-oncogene and insulin-like growth factor binding protein 3 overexpression correlates with metastatic ability in welldifferentiated pancreatic endocrine neoplasms. Clinical Cancer Research 10 6152-6158. (doi:10.1158/1078-0432.CCR-04-0285)

Hansen TB, Kjems J \& Damgaard CK 2013 Circular RNA and miR-7 in cancer. Cancer Research 73 5609-5612. (doi:10.1158/0008-5472.CAN13-1568)

Hu Y, Ou Y, Wu K, Chen Y \& Sun W 2012 miR-143 inhibits the metastasis of pancreatic cancer and an associated signaling pathway. Tumor Biology 33 1863-1870. (doi:10.1007/s13277-012-0446-8)

Iino I, Kikuchi H, Miyazaki S, Hiramatsu Y, Ohta M, Kamiya K, Kusama Y, Baba S, Setou M \& Konno H 2013 Effect of miR-122 and its target gene cationic amino acid transporter 1 on colorectal liver metastasis. Cancer Science 104 624-630. (doi:10.1111/cas.12122)

Jopling C 2012 Liver-specific microRNA-122: biogenesis and function. RNA Biology 9 137-142. (doi:10.4161/rna.18827)

Kawahara M, Kammori M, Kanauchi H, Noguchi C, Kuramoto S, Kaminishi M, Endo H \& Takubo K 2002 Immunohistochemical prognostic indicators of gastrointestinal carcinoid tumours. European Journal of Surgical Oncology 28 140-146. (doi:10.1053/ejso.2001.1229)

Kedde M, Strasser MJ, Boldajipour B, Oude Vrielink JA, Slanchev K, le Sage C, Nagel R, Voorhoeve PM, van Duijse J, Orom UA, et al. 2007 RNA-binding protein Dnd1 inhibits microRNA access to target mRNA. Cell 131 1273-1286. (doi:10.1016/j.cell.2007.11.034)

Kent OA, Chivukula RR, Mullendore M, Wentzel EA, Feldmann G, Lee KH, Liu S, Leach SD, Maitra A \& Mendell JT 2010 Repression of the miR-143/145 cluster by oncogenic Ras initiates a tumorpromoting feed-forward pathway. Genes and Development $\mathbf{2 4}$ 2754-2759. (doi:10.1101/gad.1950610)
Kent OA, McCall MN, Cornish TC \& Halushka MK 2014 Lessons from miR-143/145: the importance of cell-type localization of miRNAs. Nucleic Acids Research 42 7528-7538. (doi:10.1093/nar/gku461)

Kidd M, Modlin IM, Mane SM, Camp RL, Eick G \& Latich I 2006 The role of genetic markers-NAP1L1, MAGE-D2, and MTA1-in defining small-intestinal carcinoid neoplasia. Annals of Surgical Oncology 13 253-262. (doi:10.1245/ASO.2006.12.011)

Kidd M, Modlin IM, Pfragner R, Eick GN, Champaneria MC, Chan AK, Camp RL \& Mane SM 2007 Small bowel carcinoid (enterochromaffin cell) neoplasia exhibits transforming growth factor- $\beta 1$-mediated regulatory abnormalities including up-regulation of C-Myc and MTA1. Cancer 109 2420-2431. (doi:10.1002/cncr.22725)

Kidd M, Modlin IM \& Drozdov I 2014 Gene network-based analysis identifies two potential subtypes of small intestinal neuroendocrine tumors. BMC Genomics 15 595. (doi:10.1186/1471-2164-15-595)

Kim JG, Lee SJ, Chae YS, Kang BW, Lee YJ, Oh SY, Kim MC, Kim KH \& Kim SJ 2013 Association between phosphorylated AMP-activated protein kinase and MAPK3/1 expression and prognosis for patients with gastric cancer. Oncology 85 78-85. (doi:10.1159/000351234)

Kim HS, Lee KS, Bae HJ, Eun JW, Shen Q, Park SJ, Shin WC, Yang HD, Park M, Park WS, et al. 2015 MicroRNA-31 functions as a tumor suppressor by regulating cell cycle and epithelial-mesenchymal transition regulatory proteins in liver cancer. Oncotarget 6 8089-8102. (doi:10.18632/oncotarget)

Korpal M, Ell BJ, Buffa FM, Ibrahim T, Blanco MA, Celia-Terrassa T, Mercatali L, Khan Z, Goodarzi H, Hua Y, et al. 2011 Direct targeting of Sec23a by miR-200s influences cancer cell secretome and promotes metastatic colonization. Nature Medicine 17 1101-1108. (doi:10.1038/nm.2401)

Krell J, Stebbing J, Carissimi C, Dabrowska A, de Giorgio A, Frampton AE, Harding V, Fulci V, Macino G, Colombo T, et al. 2015 TP53 regulates miRNA association with AGO2 to remodel the miRNA-mRNA interaction network. Genome Research 26 331-341. (doi:10.1101/gr.191759.115)

Lawrence B, Gustafsson BI, Chan A, Svejda B, Kidd M \& Modlin IM 2011 The epidemiology of gastroenteropancreatic neuroendocrine tumors. Endocrinology and Metabolism Clinics of North America $\mathbf{4 0}$ 1-18. (doi:10.1016/j.ecl.2010.12.005)

Leja J, Essaghir A, Essand M, Wester K, Oberg K, Totterman TH, Lloyd R, Vasmatzis G, Demoulin JB \& Giandomenico V 2009 Novel markers for enterochromaffin cells and gastrointestinal neuroendocrine carcinomas. Modern Pathology 22 261-272. (doi:10.1038/modpathol.2008.174)

Li C, Xu B, Hirokawa M, Qian Z, Yoshimoto K, Horiguchi H, Tashiro T $\&$ Sano T 2002 Alterations of E-cadherin, $\alpha$-catenin and $\beta$-catenin expression in neuroendocrine tumors of the gastrointestinal tract. Virchows Archiv 440 145-154. (doi:10.1007/s004280100529)

Li A, Yu J, Wolfgang CL, Canto M, Hruban RH, Goggins M \& Kim H $2013 a$ MicroRNA array analysis finds elevated serum miR-1290 accurately distinguishes patients with low-stage pancreatic cancer from healthy and disease controls. Clinical Cancer Research 19 3600-3610. (doi:10.1158/1078-0432.ccr-12-3092)

Li SC, Essaghir A, Martijn C, Lloyd RV, Demoulin JB, Oberg K \& Giandomenico V 2013b Global microRNA profiling of welldifferentiated small intestinal neuroendocrine tumors. Modern Pathology 26 685-696. (doi:10.1038/modpathol.2012.216)

Liu YN, Yin JJ, Abou-Kheir W, Hynes PG, Casey OM, Fang L, Yi M, Stephens RM, Seng V, Sheppard-Tillman H, et al. 2013 MiR-1 and miR-200 inhibit EMT via Slug-dependent and tumorigenesis via Slugindependent mechanisms. Oncogene 32 296-306. (doi:10.1038/ onc.2012.58)

Liu Y-N, Yin J, Barrett B, Sheppard-Tillman H, Li D, Casey OM, Fang L, Hynes PG, Ameri AH \& Kelly K 2015 Loss of androgen regulated miR-1 activates SRC and promotes prostate cancer bone metastasis. Molecular and Cellular Biology 35 1940-1951. (doi:10.1128/ MCB.00008-15) http://erc.endocrinology-journals.org

DOI: $10.1530 /$ ERC-16-0044
(C) 2016 Society for Endocrinology Printed in Great Britain
Published by Bioscientifica Ltd 
Luzi E \& Brandi M 2011 Are microRNAs involved in the endocrinespecific pattern of tumorigenesis in multiple endocrine neoplasia type 1? Endocrine Practice 17 58-63. (doi:10.4158/EP11062.RA)

Ma J, Fang B, Zeng F, Pang H, Zhang J, Shi Y, Wu X, Cheng L, Ma C, Xia J, et al. 2014 Curcumin inhibits cell growth and invasion through up-regulation of miR-7 in pancreatic cancer cells. Toxicology Letters 231 82-91. (doi:10.1016/j.toxlet.2014.09.014)

Matthaei H, Wylie D, Lloyd MB, Dal Molin M, Kemppainen J, Mayo SC, Wolfgang CL, Schulick RD, Langfield L, Andruss BF, et al. 2012 miRNA biomarkers in cyst fluid augment the diagnosis and management of pancreatic cysts. Clinical Cancer Research 18 4713-4724. (doi:10.1158/1078-0432.CCR-12-0035)

Migliore C, Martin V, Leoni VP, Restivo A, Atzori L, Petrelli A, Isella C, Zorcolo L, Sarotto I, Casula G, et al. 2012 MiR-1 Downregulation cooperates with MACC1 in promoting MET overexpression in human colon cancer. Clinical Cancer Research 18 737-747. (doi:10.1158/1078-0432.CCR-11-1699)

Mikhaylova O, Stratton Y, Hall D, Kellner E, Ehmer B, Drew Angela F, Gallo Catherine A, Plas David R, Biesiada J, Meller J, et al. 2012 VHLregulated MiR-204 suppresses tumor growth through inhibition of LC3B-mediated autophagy in renal clear cell carcinoma. Cancer Cell 21 532-546. (doi:10.1016/j.ccr.2012.02.019)

Miller HC, Drymousis P, Flora R, Goldin R, Spalding D \& Frilling A 2014 Role of Ki-67 proliferation index in the assessment of patients with neuroendocrine neoplasias regarding the stage of disease. World Journal of Surgery 38 1353-1361. (doi:10.1007/s00268-014-2451-0)

Miller HC, Kidd M, Castellano L \& Frilling A 2015 Molecular genetic findings in small bowel neuroendocrine neoplasms: a review of the literature. International Journal of Endocrine Oncology 2 143-150. (doi:10.2217/ije.14.41)

Modlin IM, Moss SF, Chung DC, Jensen RT \& Snyderwine E 2008 Priorities for improving the management of gastroenteropancreatic neuroendocrine tumors. Journal of the National Cancer Institute $\mathbf{1 0 0}$ 1282-1289. (doi:10.1093/jnci/djn275)

Namiki T, Tanemura A, Valencia JC, Coelho SG, Passeron T, Kawaguchi M, Vieira WD, Ishikawa M, Nishijima W, Izumo T, et al. 2011 AMP kinase-related kinase NUAK2 affects tumor growth, migration, and clinical outcome of human melanoma. PNAS 108 6597-6602. (doi:10.1073/pnas.1007694108)

Namiki T, Yaguchi T, Nakamura K, Valencia JC, Coelho SG, Yin L, Kawaguchi M, Vieira WD, Kaneko Y, Tanemura A, et al. 2015 NUAK2 amplification coupled with PTEN deficiency promote melanoma development via CDK activation. Cancer Research 75 2708-2715. (doi:10.1158/0008-5472.CAN-13-3209)

Nasser MW, Datta J, Nuovo G, Kutay H, Motiwala T, Majumder S, Wang B, Suster S, Jacob ST \& Ghoshal K 2008 Down-regulation of micro-RNA-1 (miR-1) in lung cancer. Suppression of tumorigenic property of lung cancer cells and their sensitization to doxorubicininduced apoptosis by miR-1. Journal of Biological Chemistry $\mathbf{2 8 3}$ 33394-33405. (doi:10.1074/jbc.M804788200)

Norlén O, Stålberg P, Öberg K, Eriksson J, Hedberg J, Hessman O, Janson E, Hellman P \& Åkerström G 2012 Long-term results of surgery for small intestinal neuroendocrine tumors at a tertiary referral center. World Journal of Surgery 36 1419-1431. (doi:10.1007/ s00268-011-1296-z)

Osaki M, Takeshita F \& Ochiya T 2008 MicroRNAs as biomarkers and therapeutic drugs in human cancer. Biomarkers 13 658-670. (doi:10.1080/13547500802646572)

Pakala SB, Singh K, Reddy SDN, Ohshiro K, Li DQ, Mishra L \& Kumar R 2011 TGF-[beta]1 signaling targets metastasis-associated protein 1, a new effector in epithelial cells. Oncogene 30 2230-2241. (doi:10.1038/onc.2010.608)

Peng X, Guo W, Liu T, Wang X, Tu XA, Xiong D, Chen S, Lai Y, Du H, Chen G, et al. 2011 Identification of miRs-143 and -145 that is associated with bone metastasis of prostate cancer and involved in the regulation of EMT. PLoS ONE 6 e20341. (doi:10.1371/journal. pone.0020341)

Pfragner R, Wirnsberger G, Niederle B, Behmel A, Rinner I, Mandl A, Wawrina F, Luo J, Adamiker D, Hoger H, et al. 1996 Establishment of a continuous cell line from a human carcinoid of the small intestine (KRJ-I). International Journal of Oncology 8 513-520. (doi:10.3892/ ijo.8.3.513)

Pfragner R, Behmel A, Hoger H, Beham A, Ingolic E, Stelzer I, Svejda B, Moser VA, Obenauf AC, Siegl V, et al. 2009 Establishment and characterization of three novel cell lines - P-STS, L-STS, H-STS derived from a human metastatic midgut carcinoid. Anticancer Research 29 1951-1961

Reddy SK \& Clary BM 2010 Neuroendocrine liver metastases. Surgical Clinics of North America 90 853-861. (doi:10.1016/j.suc.2010.04.016)

Reid JF, Sokolova V, Zoni E, Lampis A, Pizzamiglio S, Bertan C, Zanutto S, Perrone F, Camerini T, Gallino G, et al. 2012 miRNA profiling in colorectal cancer highlights miR-1 involvement in METdependent proliferation. Molecular Cancer Research 10 504-515. (doi:10.1158/1541-7786.MCR-11-0342)

Reidy-Lagunes DL, Vakiani E, Segal MF, Hollywood EM, Tang LH, Solit DB, Pietanza MC, Capanu M \& Saltz LB 2012 A phase 2 study of the insulin-like growth factor-1 receptor inhibitor MK-0646 in patients with metastatic, well-differentiated neuroendocrine tumors. Cancer 118 4795-4800. (doi:10.1002/cncr.27459)

Roldo C, Missiaglia E, Hagan JP, Falconi M, Capelli P, Bersani S, Calin GA, Volinia S, Liu CG, Scarpa A, et al. 2006 MicroRNA expression abnormalities in pancreatic endocrine and acinar tumors are associated with distinctive pathologic features and clinical behavior. Journal of Clinical Oncology 24 4677-4684. (doi:10.1200/ JCO.2005.05.5194)

Ruebel K, Leontovich AA, Stilling GA, Zhang S, Righi A, Jin L \& Lloyd RV 2010 MicroRNA expression in ileal carcinoid tumors: downregulation of microRNA-133a with tumor progression. Modern Pathology 23 367-375. (doi:10.1038/modpathol.2009.161)

Sacconi A, Biagioni F, Canu V, Mori F, Di Benedetto A, Lorenzon L, Ercolani C, Di Agostino S, Cambria AM, Germoni S, et al. 2012 miR204 targets Bcl-2 expression and enhances responsiveness of gastric cancer. Cell Death and Disease 3 e423. (doi:10.1038/cddis.2012.160)

Sandhu V, Bowitz Lothe IM, Labori KJ, Lingiærde OC, Buanes T, Dalsgaard AM, Skrede ML, Hamfjord J, Haaland T, Eide TJ, et al. 2015 Molecular signatures of mRNAs and miRNAs as prognostic biomarkers in pancreatobiliary and intestinal types of periampullary adenocarcinomas. Molecular Oncology 9 758-771. (doi:10.1016/j. molonc.2014.12.002)

Siomi H \& Siomi MC 2010 Posttranscriptional regulation of microRNA biogenesis in animals. Molecular Cell 38 323-332. (doi:10.1016/j. molcel.2010.03.013)

Spahn M, Kneitz S, Scholz C-J, Stenger N, Rüdiger T, Ströbel P, Riedmiller H \& Kneitz B 2010 Expression of microRNA-221 is progressively reduced in aggressive prostate cancer and metastasis and predicts clinical recurrence. International Journal of Cancer $\mathbf{1 2 7}$ 394-403. (doi:10.1002/ijc.24715)

Svejda B, Kidd M, Kazberouk A, Lawrence B, Pfragner R \& Modlin IM 2011 Limitations in small intestinal neuroendocrine tumor therapy by mTor kinase inhibition reflect growth factor-mediated PI3K feedback loop activation via ERK1/2 and AKT. Cancer 117 4141-4154. (doi:10.1002/cncr.26011)

Svejda B, Kidd M, Timberlake A, Harry K, Kazberouk A, Schimmack S, Lawrence B, Pfragner R \& Modlin IM 2013 Serotonin and the 5-HT7 receptor: The link between hepatocytes, IGF-1 and small intestinal neuroendocrine tumors. Cancer Science 104 844-855. (doi:10.1111/ cas.12174)

Takagi T, Iio A, Nakagawa Y, Naoe T, Tanigawa N \& Akao Y 2009 Decreased expression of microRNA-143 and -145 in human gastric cancers. Oncology 77 12-21. (doi:10.1159/000218166)
(C) 2016 Society for Endocrinology Printed in Great Britain
Published by Bioscientifica Ltd 
Toiyama Y, Hur K, Tanaka K, Inoue Y, Kusunoki M, Boland CR \& Goel A 2014 Serum miR-200c is a novel prognostic and metastasis-predictive biomarker in patients with colorectal cancer. Annals of Surgery 259 735-743. (doi:10.1097/SLA.0b013e3182a6909d)

Van Buren G, Rashid A, Yang AD, Abdalla EK, Gray MJ, Liu W, Somcio R, Fan F, Camp ER, Yao JC, et al. 2007 The development and characterization of a human midgut carcinoid cell line. Clinical Cancer Research 13 4704-4712. (doi:10.1158/1078-0432.CCR-06-2723)

Viré E, Curtis C, Davalos V, Git A, Robson S, Villanueva A, Vidal A, Barbieri I, Aparicio S, Esteller M, et al. 2014 The breast cancer oncogene EMSY represses transcription of antimetastatic microRNA miR-31. Molecular Cell 53 806-818. (doi:10.1016/j. molcel.2014.01.029)

Weber F, Teresi RE, Broelsch CE, Frilling A \& Eng C 2006 A limited set of human microRNA is deregulated in follicular thyroid carcinoma. Journal of Clinical Endocrinology and Metabolism 91 3584-3591. (doi:10.1210/jc.2006-0693)

White NMA, Khella HWZ, Grigull J, Adzovic S, Youssef YM, Honey RJ, Stewart R, Pace KT, Bjarnason GA, Jewett MAS, et al. 2011 miRNA profiling in metastatic renal cell carcinoma reveals a tumoursuppressor effect for miR-215. British Journal of Cancer $\mathbf{1 0 5}$ 1741-1749. (doi:10.1038/bjc.2011.401)

Xing TJ, Xu HT, Yu WQ \& Jiang DF 2013 Methylation regulation of liverspecific microRNA-122 expression and its effects on the proliferation and apoptosis of hepatocellular carcinoma cells. Genetics and Molecular Research 12 3588-3597. (doi:10.4238/2013.September.13.3)

Xu K, Chen Z, Qin C \& Song X 2014 miR-7 inhibits colorectal cancer cell proliferation and induces apoptosis by targeting XRCC2. OncoTargets and Therapy 7 325-332. (doi:10.2147/ott.s59364)

Yan D, Dong Xda E, Chen X, Wang L, Lu C, Wang J, Qu J \& Tu L 2009 MicroRNA-1/206 targets c-Met and inhibits rhabdomyosarcoma development. Journal of Biological Chemistry 284 29596-29604. (doi:10.1074/jbc.M109.020511)
Yin Y, Zhang B, Wang W, Fei B, Quan C, Zhang J, Song M, Bian Z, Wang Q, Ni S, et al. 2014 miR-204-5p inhibits proliferation and invasion and enhances chemotherapeutic sensitivity of colorectal cancer cells by downregulating RAB22A. Clinical Cancer Research 20 6187-6199. (doi:10.1158/1078-0432.CCR-14-1030)

Yip L, Kelly L, Shuai Y, Armstrong M, Nikiforov Y, Carty S \& Nikiforova M 2011 MicroRNA signature distinguishes the degree of aggressiveness of papillary thyroid carcinoma. Annals of Surgical Oncology 18 2035-2041. (doi:10.1245/s10434-011-1733-0)

Yoshino H, Chiyomaru T, Enokida H, Kawakami K, Tatarano S, Nishiyama K, Nohata N, Seki N \& Nakagawa M 2011 The tumour-suppressive function of miR-1 and miR-133a targeting TAGLN2 in bladder cancer. British Journal of Cancer 104 808-818. (doi:10.1038/bjc.2011.23)

Zhang B, Pan X, Cobb GP \& Anderson TA 2007 microRNAs as oncogenes and tumor suppressors. Developmental Biology 302 1-12. (doi:10.1016/j.ydbio.2006.08.028)

Zhang L, Wang X \& Chen P 2013 MiR-204 down regulates SIRT1 and reverts SIRT1-induced epithelial-mesenchymal transition, anoikis resistance and invasion in gastric cancer cells. BMC Cancer 13290. (doi:10.1186/1471-2407-13-290)

Zhang H, Cai K, Wang J, Wang X, Cheng K, Shi F, Jiang L, Zhang Y \& Dou J 2014 MiR-7, inhibited indirectly by LincRNA HOTAIR, directly inhibits SETDB1 and reverses the EMT of breast cancer stem cells by downregulating the STAT3 pathway. Stem Cells 32 2858-2868. (doi:10.1002/stem.1795)

Zhao X, Dou W, He L, Liang S, Tie J, Liu C, Li T, Lu Y, Mo P, Shi Y, et al. 2013 MicroRNA-7 functions as an anti-metastatic microRNA in gastric cancer by targeting insulin-like growth factor-1 receptor. Oncogene 32 1363-1372. (doi:10.1038/onc.2012.156)

Zhu C, Ren C, Han J, Ding Y, Du J, Dai N, Dai J, Ma H, Hu Z, Shen H, et al. 2014 A five-microRNA panel in plasma was identified as potential biomarker for early detection of gastric cancer. British Journal of Cancer 110 2291-2299. (doi:10.1038/bjc.2014.119)

Received in final form 8 June 2016

Accepted 27 June 2016

Accepted Preprint published online 27 June 2016
() 2016 Society for Endocrinology Printed in Great Britain
Published by Bioscientifica Ltd 